\title{
CRYPTIC ARTERIOVENOUS AND VENOUS HAMARTOMAS OF THE BRAIN
}

\author{
BY \\ J. V. CRAWFORD and DOROTHY S. RUSSELL
}

From the Neurosurgical Department and Bernhard Baron Institute of Pathology, The London Hospital

In any large series of cases of spontaneous cerebral haemorrhage there are some of obscure aetiology that have certain clinical features in common. They occur in the younger age-groups, and although the onset of symptoms may be sudden, loss of consciousness is often delayed or incomplete. The cause of the bleeding often remains obscure on clinical examination and full investigation. Before the catastrophe the patient's condition has given no hint of any latent cerebral lesion. Although ultimate anatomical examination may reveal a vascular anomaly, the responsible lesion may be difficult to locate both on account of its situation and small size. For these reasons we propose the name " cryptic" for the series to be described. The incidence of these cryptic hamartomas in a total necropsy series of 461 examples of spontaneous intracranial haemorrhage, with a brief morphological account, has been published by one of us (Russell, 1954).

\section{MATERIAL}

This series comprises a total of 20 cases derived both from the Neurosurgical Department (seven with survival after operation) and the necropsy records (13) of the London Hospital. All were under 40 years of age, 15 being under 20 years. The sex distribution is 11 males to nine females.

The cases are divided into three groups according to the anatomical situation of the lesion : Group I, related to the cerebral convexities ; Group II, central cerebral ; and Group III, cerebellar.

\section{GROUP I}

This group comprises 10 cases, six of which came to necropsy (Table 1). A fuller account of Cases 6,8 , and 9 is given below for illustrative purposes.

\section{Clinical Summary}

As a rule the neurological disturbance comes without warning, usually during the daytime. The subject, having been perfectly well, collapses at school or in the street, or in other unprovocative circumstances. Complaint of intense headache is accompanied by vomiting and shock. Convulsions sometimes occur. The pupils are often inactive and there may be a strabismus. Flaccidity of the limbs is followed by spasticity on one or both sides of the body, with extensor plantar responses. Involuntary movements of the limbs may occur in association with intraventricular haemorrhage. At a varying interval drowsiness deepens to coma, with cyanosis, stertorous breathing, and a full, bounding pulse. In the fatal cases, deeply bloodstained fluid is often obtained by lumbar puncture, because of the $\stackrel{\Phi}{\circ} 7$ frequency of ventricular haemorrhage. In these $\frac{\mathbb{D}}{\sigma}$ cases death has followed within a few hours or days of the onset.

\section{Pathology}

In all but two examples in this series, the lesion was in the area of supply of the middle cerebral artery ; one each lay in the areas of the anterior and posterior arteries respectively. The left hemisphere was affected in six, the right in four cases. On inspection the lesion sometimes appeared on the surface (Case 9 ; Fig. 1) as a small cluster of

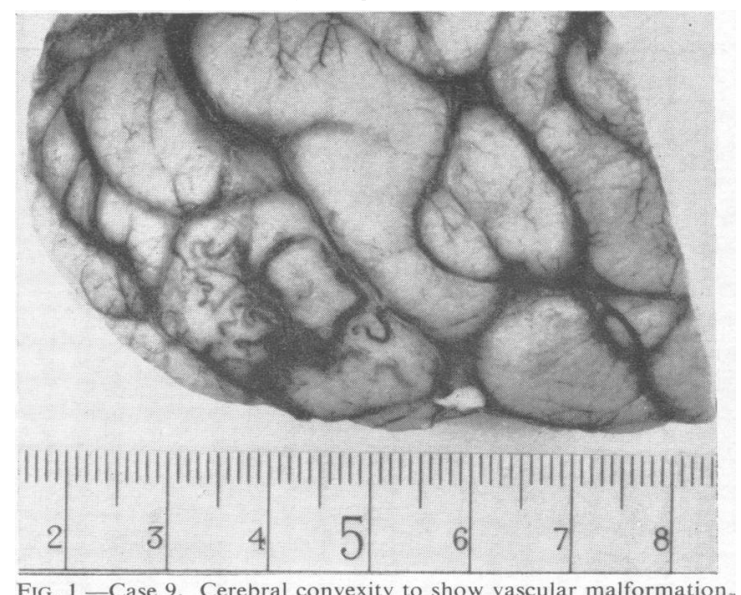

FIG, 1.-Case 9. Cerebral convexity to show vascular malformation. 
TABLE I

GROUP I

\begin{tabular}{|c|c|c|c|c|c|c|}
\hline $\begin{array}{l}\text { Series } \\
\text { No. }\end{array}$ & Age & Sex & Territory & $\begin{array}{l}\text { Duration of } \\
\text { Symptoms }\end{array}$ & Main Clinical Features & Operative/Necropsy Findings \\
\hline 1 & 3 & $\mathbf{F}$ & $\begin{array}{l}\text { R. mid. } \\
\text { cerebral }\end{array}$ & $\begin{array}{l}12 \text { hours. } \\
\text { Fatal }\end{array}$ & $\begin{array}{l}\text { Sudden collapse. L.-sided convulsions. Died } \\
\text { in status epilepticus }\end{array}$ & $\begin{array}{l}\text { Tortuous enlarged veins upper parietal } \\
\text { region. Underlying haematoma } 7 \times 6 \times 3 \\
\text { cm. Ventricular and slight subarachnoid } \\
\text { haemorrhage. Microscopy : arterio- } \\
\text { venous hamartoma penetrating cortex }\end{array}$ \\
\hline 2 & 15 & $\mathbf{M}$ & $\begin{array}{l}\text { L. mid. } \\
\text { cerebral }\end{array}$ & 2 hours. & $\begin{array}{l}\text { Collapsed in street. Admitted moribund. } \\
\text { Died on way to ward }\end{array}$ & $\begin{array}{l}\text { Haematoma } 10 \times 2 \times 2 \mathrm{~cm} \text {. in centrum } \\
\text { semiovale. Ventricular haemorrhage. No } \\
\text { vascular lesion seen. Microscopy : } \\
\text { structural changes (arteries) in depths of } \\
\text { Sylvian fissure; suggestive but not } \\
\text { conclusive }\end{array}$ \\
\hline 3 & 16 & $\mathbf{F}$ & $\begin{array}{l}\text { R. mid. } \\
\text { cerebral }\end{array}$ & 7 hours. & $\begin{array}{l}\text { Sudden collapse. Vomiting. Coma. Clonic } \\
\text { spasms. Absent reflexes. Steady deteriora- } \\
\text { tion }\end{array}$ & $\begin{array}{l}\text { Arteriovenous malformation } 3 \times 0.5 \mathrm{~cm} \text {. } \\
\text { over ascending parietal. } \\
\text { haemorrhage. Ventricular } \\
\text { venous hamartoma penetrating cortex to } \\
\text { white matter }\end{array}$ \\
\hline 4 & 24 & $\mathbf{F}$ & $\begin{array}{l}\text { L. mid. } \\
\text { cerebral }\end{array}$ & 2 weeks. & $\begin{array}{l}\text { Onset severe headaches. A week later mild } \\
\text { dysphasia. O.E. papilloedema and mild } \\
\text { R. hemiparesis with sensory loss. Clinically } \\
\text { regarded as glioma. Ventriculography : a } \\
\text { L.-sided haematoma encountered. Cranio- } \\
\text { tomy performed }\end{array}$ & $\begin{array}{l}\text { Temporo-parietal haematoma evacuated. } \\
\text { Leash of abnormal vessels seen. Biopsy : } \\
\text { abnormal vein in cortex; otherwise } \\
\text { granulation tissue and gliosis only. Known } \\
\text { to be well } 4 \text { years later }\end{array}$ \\
\hline 5 & 32 & $\mathbf{F}$ & $\begin{array}{l}\text { L. post } \\
\text { cerebral }\end{array}$ & 4 days. & $\begin{array}{l}8 \text { months pregnant. Sudden collapse. Re- } \\
\text { mained semi-comatose, fixed pupils and } \\
\text { R. hemiplegia. Gradually deepened into } \\
\text { coma. L. sub-temporal decompression per- } \\
\text { formed, but she continued to deteriorate }\end{array}$ & $\begin{array}{l}\text { Arteriovenous malformation } 1.2 \times 0.7 \mathrm{~cm} \text {. } \\
\text { ventral occipital. Haematoma } 10 \times 3.5 \times 2 \\
\mathrm{~cm} \text {. temporo-occipital. Subarachnoid and } \\
\text { subdural haemorrhage. Microscopy } \\
\text { arteriovenous hamartoma (Fig. 3) }\end{array}$ \\
\hline 6 & 12 & $\mathbf{M}$ & L. ant. & $\begin{array}{l}3 \text { episodes } \\
\text { in } 3 \text { years. } \\
\text { Fatal haem- } \\
\text { orrhage }\end{array}$ & See case report & See case report \\
\hline 7 & 32 & $\mathbf{M}$ & L. mid. & $\begin{array}{l}2 \text { episodes } \\
4 \text { years } \\
\text { apart. Sur- } \\
\text { vived }\end{array}$ & $\begin{array}{l}1947 \text { L. cerebral haemorrhage. Symptoms } \\
\text { subsided spontaneously over weeks. 1951 } \\
\text { recurrence with dysphasia, hemiparesis, and } \\
\text { hemianopia. Angiogram confirmed L. } \\
\text { temporo-parietal mass; no abnormal } \\
\text { vessels seen }\end{array}$ & $\begin{array}{l}\text { Temporo-parietal haematoma evacuated } \\
\text { Leash of abnormal vessels seen in medial } \\
\text { wall of haematoma adjacent to ventricle } \\
\text { Biopsy : enlarged tortuous arteries and } \\
\text { veins in adjacent pia. Known to be well }\end{array}$ \\
\hline 8 & 16 & $\mathbf{F}$ & cerebral & 6 weeks. & See case report & See case report \\
\hline 9 & 8 & $\mathbf{M}$ & $\begin{array}{l}\text { R. mid. } \\
\text { cerebral }\end{array}$ & $\begin{array}{l}12 \text { hours. } \\
\text { Fatal }\end{array}$ & See case report & See case report \\
\hline 10 & 11 & $\mathbf{F}$ & $\begin{array}{l}\text { L. mid. } \\
\text { cerebral }\end{array}$ & $8 \underset{\text { days. }}{\text { Survived }}$ & $\begin{array}{l}\text { Sudden onset intense headache lapsing into } \\
\text { semi-coma. Remained stationary. O.E. } \\
\text { aphasic, papilloedema, R. hemiparesis with } \\
\text { movements of R. arm. Arteriogram suggests } \\
\text { L. parietal mass, no abnormal vessels. } \\
\text { Ventriculogram haematoma-cavity entered } \\
\text { on L. Craniotomy performed }\end{array}$ & $\begin{array}{l}\text { Temporo-parietal haematoma exposed and } \\
\text { evacuated. Leash of abnormal vessels } \\
\text { seen in the antero-medial wall of the cavity } \\
\text { adjacent to the ventricle. No biopsy. } \\
\text { Known to be well }\end{array}$ \\
\hline
\end{tabular}

tortuous and dilated vessels related to the underlying haematoma. But sometimes it was buried in the depths of a sulcus while the surface vessels appeared quite normal (Case 6 ; Fig. 2). It is indeed likely, as perhaps in Case 2, that certain of these deeper lesions are destroyed in the event of a large haemorrhage. We have in our own necropsy records certain other cases, excluded from this study, in young subjects in whom the source of a large spontaneous haemorrhage has not been demonstrated. The frequent absence of any enlargement and tortuosity of the vessels upon the adjacent surface of the brain is an important reason why their demonstration is, in any event, apt to be difficult.
The size of the haematoma has varied considerably. In our necropsies the smallest measured 3 by 0.5 $\mathrm{cm}$.; the largest 10 by 3.5 by $2 \mathrm{~cm}$. But in four of these six cases the ventricular system was also involved. In addition to leptomeningeal haemorrhage, subdural haemorrhage occurred in Cases 5 and 6 ; the latter was doubtless due to rupture of the arachnoid membrane under pressure.

Microscopically, these vascular hamartomas are composed of enlarged and tortuous arteries and veins occupying a restricted area of the pia and subjacent cerebrum in the region of the haemorrhage (Figs. 2, 3). As in the better known larger lesions, the intima and media are structurally abnormal, the muscular and elastic elements displaying a hap- 


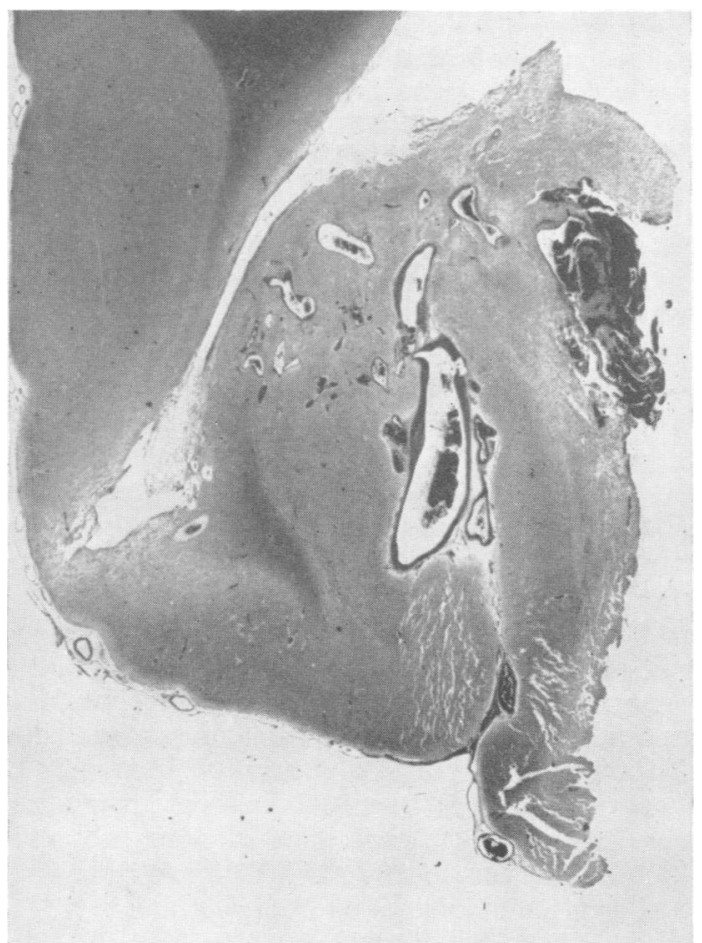

FIG. 2.-Case 6. Coronal section through gyrus rectus (left) containing cavity, and border of recent haemorrhage (right). Between these, and in depths of sulcus, tissue occupied by arteriovenous hamartoma. Haematoxylin and eosin. $\times 3$ approx.

hazard hyper- or hypoplasia. The intima is often thickened by cushions of fibromuscular tissue. Fibrous thickening of a more diffuse character usually affects the veins.

Variable amounts of fibrillary gliosis are found in the intervening neural tissues and, occasionally, foci of macrophages containing haemosiderin representing previous leakages of blood.

\section{Illustrative Cases}

Case 6 (Neurosurg. No. 5960/49).-A boy, age 12, was admitted on June 8, 1949.

Clinical History.-Three years before admission to the London Hospital he had an episode of intense headache and neck stiffness which lasted two days. Three months ago he had another attack of headache and was admitted to a local hospital. Lumbar puncture yielded bloodstained cerebrospinal fluid. He rapidly improved and was free of symptoms at the time of his admission for investigation. Examination revealed no abnormal physical signs. He was right-handed. On June 13, carotid angiography was performed under general anaesthesia. The $x$-ray pictures showed in one projection an abnormal collection of fine vessels in the left frontal region (Fig. 4). Following this procedure he remained unconscious for some hours and was then

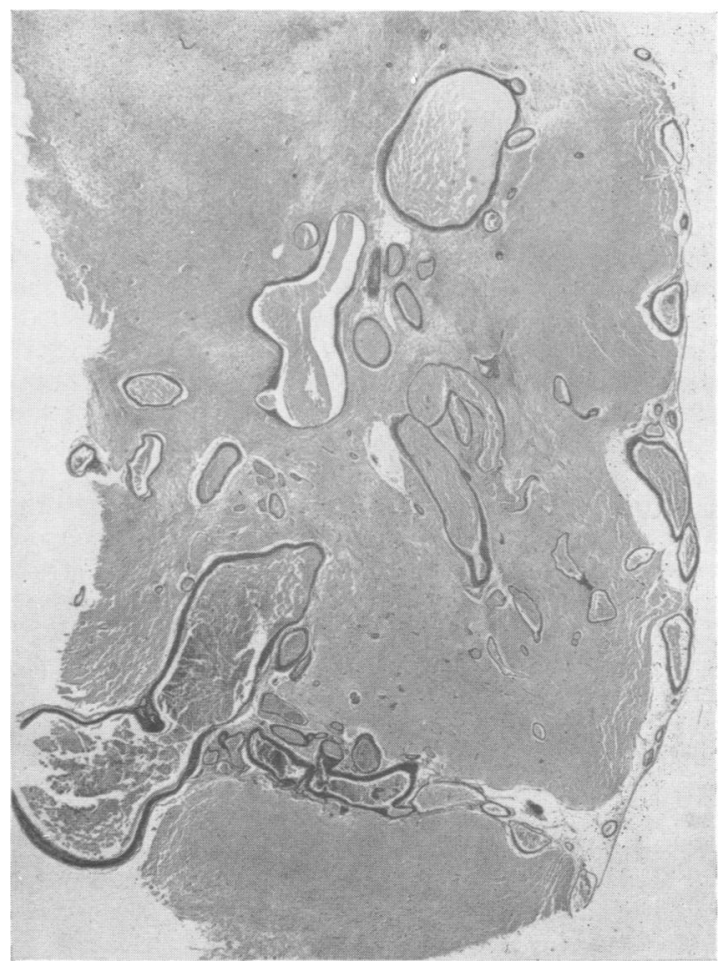

FIG. 3.-Case 5. Temporo-occipital cortex in border of haematoma showing malformed vessels in meninges and cortex. Phosphotungstic-acid haematoxylin. $\times 7$.

found to be aphasic and to have a right hemiplegia. He $\overrightarrow{0}$ improved steadily. Two weeks later he was making only occasional mistakes in his speech, his right leg was

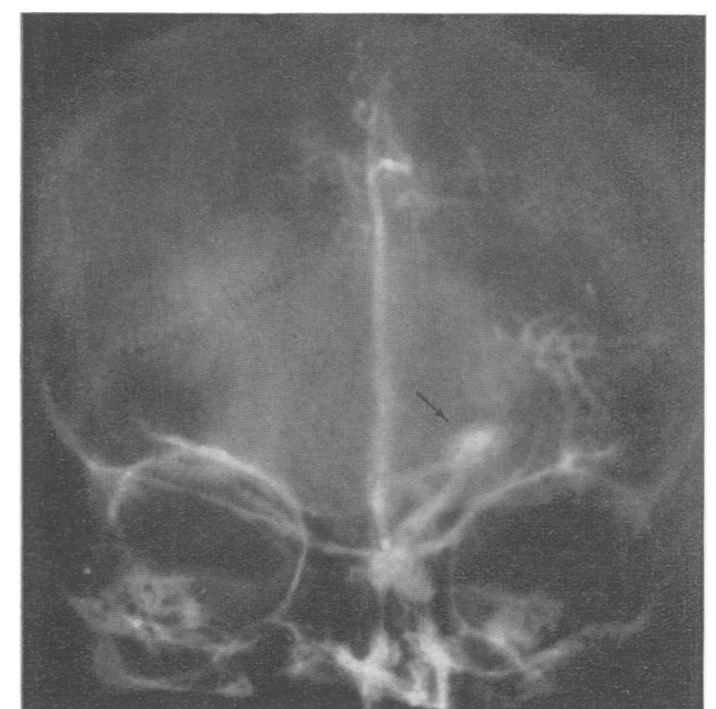

Fig. 4.-Case 6. Angiogram to show vascular abnormality (arrow). 
normal, but his right hand remained clumsy and weak. A course of deep $x$ rays was given to the left frontal angioma. On July 21 , a few hours before going home, he suddenly developed intense headache, became aphasic, and started having right-sided convulsions. He passed into coma and died within an hour of this.

Pathology.-Necropsy (P.M. 263/49) was limited to examination of the brain. An interrupted layer of recent blood clot occupied the subdural space over the cerebral hemispheres, the left side being mainly affected. The left frontal pole was expanded by similar clot, part of which escaped during removal of the brain. There was orange pigmentation of the leptomeninges over the left gyrus rectus and adjacent medial surface of the frontal pole. No visible abnormality was found on dissection of the circle of Willis and the main cerebral arteries, the left middle and anterior cerebral vessels being fully dissected. The main dural venous sinuses contained fluid blood. The left common carotid artery showed two puncture wounds $2.5 \mathrm{~cm}$. below its bifurcation but was otherwise macroscopically and microscopically normal. On coronal section of the fixed brain, the white matter of the left frontal lobe contained two cavities of about equal size. The more medial, measuring $5 \mathrm{~cm}$. dorsiventrally by $1 \mathrm{~cm}$. from side to side and $4.5 \mathrm{~cm}$. from before back, extended into the subcortical white matter of the gyrus rectus and posteriorly almost reached the ependyma of the frontal horn. Its walls were smooth and glistening, with patches of caféau-lait staining; a few filaments and membranes of soft grey tissue traversed the space. The more lateral cavity was separated from the medial one by a partition of white matter $0.5 \mathrm{~cm}$. thick. Its walls were of soft, ragged white matter containing a few fragments of recent clot (Fig. 2).

Apart from these cavities an old friable infarct occupied the cortex of the left middle frontal convolution, extending from the coronal level of the genu of the corpus callosum to involve the inferior frontal convolution, the adjacent operculum, and part of the corona radiata. Similar infarction affected a large area of the parietooccipital cortex, ending $3 \mathrm{~cm}$. in front of the occipital pole. There was considerable pultaceous softening of the subcortical white matter in the occipital lobe. The rest of the brain appeared normal.

Microscopic Examination.-Although unseen macroscopically, two of the four sections taken through the cavities in the frontal pole reveal an arteriovenous malformation related to both (Fig. 2). It occupies the cortex and subcortical white matter of the inferior aspect of the lobe in the depths of a sulcus, and is supplied by abnormally large, malformed vessels in the leptomeninges. The enlarged and tortuous elements of this lesion are individually separated by neural tissues in which there is considerable focal gliosis. One of the vessels is partly occluded by recent thrombus and there is recent haemorrhage in its immediate neighbourhood.

The medial cavity extends into the cortex; it is lined with a thin layer of organized granulation tissue containing small lymphocytes and many pigmented macrophages. The walls of the lateral cavity are composed of ragged oedematous cortex and white matter containing small recent haemorrhages. Sections from the infarcted areas in the posterior frontal and parietal lobes confirm the macroscopic appearances of old anaemic infarcts. None of the meningeal arteries bears evidence of previous occlusion, but the adventitia of a small artery in the parietal region contains a small group of foreign-body giant cells.

The medial cavity in the frontal pole represents the site of an old haemorrhage corresponding either to the initial disturbance recorded three years ago, or to the more recent incident three months ago. From evidence published elsewhere (Russell, 1954) the more recent of these dates may be excluded. The pigmentation of the adjacent leptomeninges testifies to its leakage in the region of the gyrus rectus. The lateral cavity is obviously the result of a terminal haemorrhage. This also gave way into the leptomeninges and, presumably from sudden focal pressure, into the subdural space.

The pathological examination does not establish the origin of the infarcts in the hinder part of the left cerebrum. But the group of foreign-body giant cells in the adventitia of one meningeal artery suggests the escape there of some substanco which excited this reaction and that substance mas have been the diodone used in angiography.

Case 8 (L.H. No. 34458/51). - A girl, aged 16, was admitted on September 16, 1951.

Clinical History.-For six weeks before admission she suffered frequent bifrontal headache, often severe. enough to stop her from working. She had never before had headaches. One night, three weeks ago, she awoke feeling sick and could not use her limbs properly. She became semiconscious. On admission to a local hospital neck rigidity and a left hemiplegia were noted. Lumbar puncture yielded heavily bloodstained fluid. During the first week in hospital her level of consciousness gradually improved. On transfer to The London Hospital she was alert and orientated. There was moderate neck stiffness and positive Kernig's sign. The fundi were normal. She had a complete flaccid left hemiplegia with analgesia, hypoaesthesia, and postural loss on the left. Plantar responses were $\downarrow \uparrow$. On September 19, right carotid angiography showed a very small irregular vascular malformation in the parietal region with evidence of an adjacent intracerebral mass (Fig. 5). On September 25, a right lateral osteoplastic flap was raised and a centro-parietal intracerebral haematoma evacuated. In the posterior wall of the haematoma there was a small knot of blood vessels, a few millimetres wide, going down into a tougher piece of clot. This was removed for histological study. Vessels were then encountered passing through a thin septum between the cavity and the lateral ventricle. These were coagulated. Her post-operative course was uneventful. A post-operative angiogram (on October 5) showed the small hamartoma to have been removed (Fig. 6). At the time of her discharge (November 13) there was still 


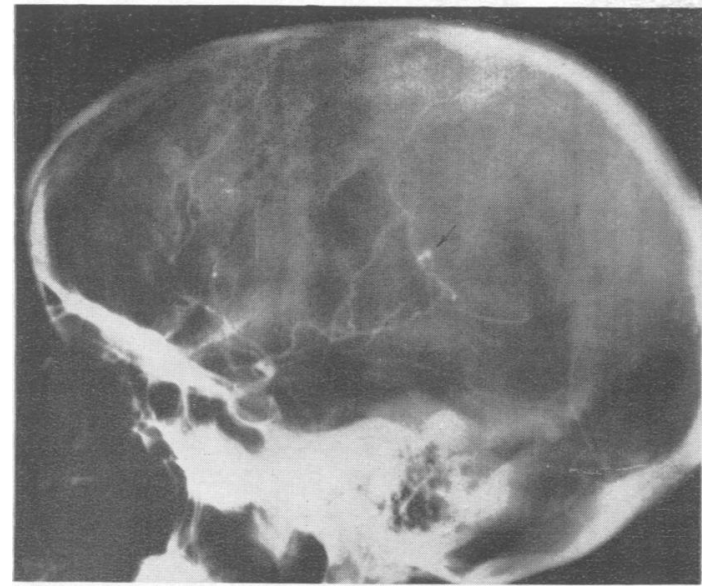

FIG. 5.-Case 8. Angiogram to show vascular abnormality before operation (arrow).

considerable residual weakness of the left face, arm, and leg. She was able to walk when fitted with a toespring. Some sensory loss also persisted on the left. She has been seen at regular intervals and still shows a severe left spastic hemiparesis, most apparent in the hand. She is able to do most housework, however, and walks quite well with a lateral iron.

Pathology.-Small fragments of recent clot, granulation tissue, cerebral cortex, and white matter were received. In the latter there are several greatly enlarged vessels with stout collagenous walls and no elastic tissue, which are probably altered veins. In the few arteries identified there is some reduplication of the internal elastic lamella, but they are not otherwise abnormal. Abundant foam cells, often containing granules of iron-pigment, occupy the granulation tissue.

Case 9 (L.H. No. 2628/54). - A boy, aged 8, was admitted on January $25,1954$.

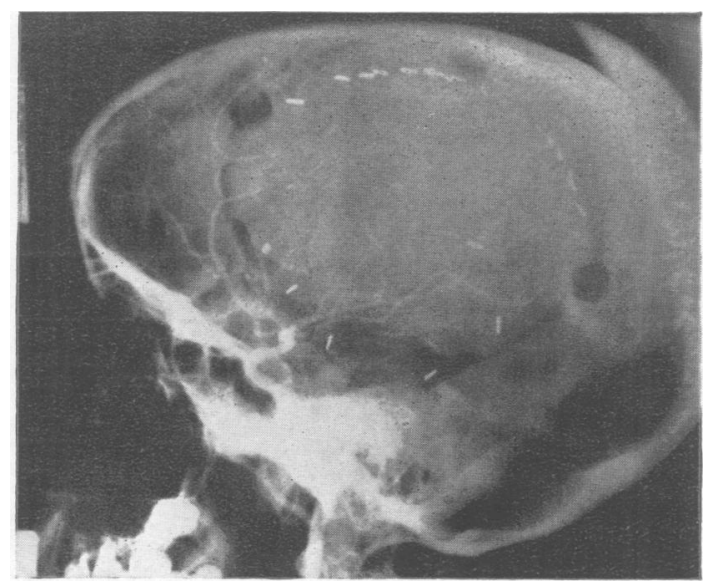

Fig. 6.-Case 8. Angiogram following operation. A silver clip indicates neighbourhood of extirpated lesion.

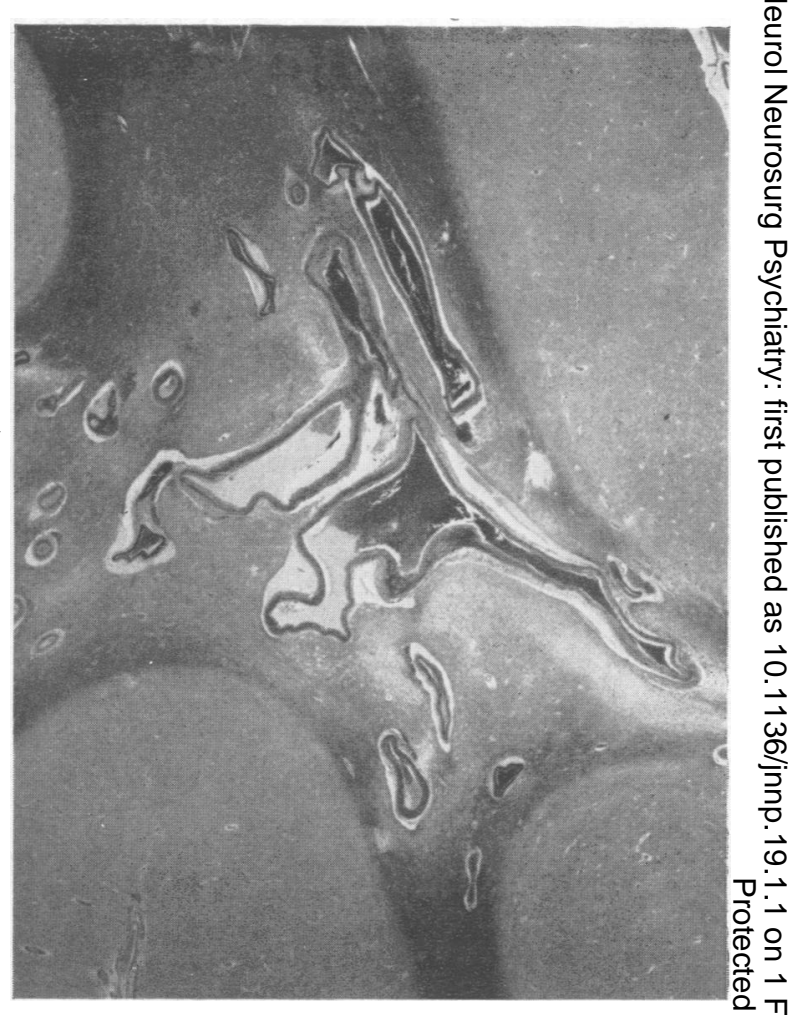

FIG. 7.-Case 9. Subcortical anomalous vessels below focus shown $\frac{\sigma}{\sigma}$ in Fig. 1. Phosphotungstic-acid haematoxylin. $\times 9$.

Clinical History.-About eight hours before admission he received a slight blow on the back of the neck; five $\overrightarrow{0}$ hours later he returned from school with intense headache and vomiting. He gradually lost consciousness and by the time of his admission he was in coma. There were frequent jerking movements of all the limbs and frothing at the mouth, and occasional episodes of Cheyne-Stokes respiration. He had marked neck stiffness ; the pupils were dilated and fixed, and the corneal reflexes were absent. Both plantar responses were extensor. Biparietal and bitemporal burr-holes were made to exclude surface haematoma. Heavily bloodstained fluid was found in both lateral ventricles. His condition became desperate and he died three hours later (12 hours after the onset of symptoms).

Pathology.-No abnormalities were observed at necropsy (P.M. 29/54) apart from the brain. The cerebral hemispheres were moderately flattened. All the main cerebral arteries appeared normal and symmetrical. The right occipital lobe was expanded by a haematoma, measuring 3 by $1.5 \mathrm{~cm}$., which occupied the white matter between the ventricle and the junction of the right superior and inferior parietal lobules posteriorly ; it had ruptured into the ventricle. On the adjacent surface of the brain, the leptomeninges contained a cluster of dilated blood vessels measuring about $1.5 \mathrm{~cm}$. diameter (Fig. 1). Immediately beneath this and 
abutting on the haematoma, a group of vessels with thickened walls was visible under magnification, the patch so occupied measuring less than $1 \mathrm{~cm}$. Further examination of the brain revealed haemorrhage throughout the ventricular system. There was no abnormality in the cervical spine and cord.

Microscopic Examination.-The subcortical focus is composed of enlarged, tortuous, malformed vessels (Fig. 7). Most of these are veins with thickened collagenous walls containing scanty and irregularly distributed muscle fibres. A few arteries in the area are enlarged with abnormally developed elastica. In the tissue between the vessels there is patchy gliosis, severe focal oedema, and recent haemorrhage. Near the ventricle there is free iron-pigment in macrophages adjacent to some of the vessels, and an ill-defined group of foam cells. It is evident from this that slight leakage of blood had taken place at some antecedent period.

\section{GROUP II}

The four cases in which a central cerebral arteriovenous malformation was demonstrated all came to necropsy (Table II).

\section{Clinical Summary}

The resemblance between these and the rapidly fatal examples of Group I is close. The onset was similarly dramatic with progression into deep coma followed by death within a few hours, or on the following day. The clinical data available are scanty and provide no distinctive features by which the site of the haemorrhage could be identified. From the nature and location of the lesions in this group it is most unlikely that any form of active treatment could avail.

\section{Pathology}

To the naked eye these lesions were either entirely or predominantly venous, involving to a variable extent the tributaries of one of the lesser veins of Galen, and, in the grosser examples, the latter as well. Thus in Case 14 the right lesser vein of Galen was dilated together with its tributaries, the latter being distinctly tortuous. Many slightly dilated vessels were observed, on section, in the pulvinar. Plexiform dilatation of some arteries was found in the meninges between the right crus and the adjacent hippocampus. Death was due to massive intraventricular haemorrhage together with a small haematoma in the substance of the right optic thalamus. Microscopically the right thalamus, and in particular the pulvinar, is riddled with dilated and tortuous arteries and veins; the adjacent choroid plexus is similarly affected (Figs. 8 and 9).

In view of the anatomical situation of these vascular anomalies a large and fatal intraventricular haemorrhage is apt to be the outcome. On the other hand, the lesion, like those described in Group I, may be small and difficult to demonstrate. In such the haemorrhage may lie in the centrum semiovale, as in the example now to be described.

\section{Illustrative Case}

Case 13 (L.H. No. 31096/38). - A boy, aged 11, was admitted on July 9, 1938.

Clinical History.-Eight hours before admission he collapsed at school and became drowsy. On admissiono.he had a flaccid paralysis of the right arm and lego Lumbar puncture yielded clear fluid under slightl迎 increased pressure. Overnight the child deteriorated $\overrightarrow{\mathrm{D}}-$ lapsing into coma. Slight neck rigidity was noted. The $T$ left pupil was larger than the right. The right arm and 응 leg were now spastic. Respirations became irregulą and he died 22 hours after the onset of symptoms.

Pathology.-Significant findings at necropsy (P.M $295 / 38$ ) in this case were restricted to the brain. The left cerebrum was considerably and diffusely expanded: The meninges, the main cerebral arteries and veins and their branches all appeared normal. A recent massive haematoma, measuring $8 \mathrm{~cm}$. from before back by $7 \mathrm{~cm}$. dorsiventrally and up to $4 \mathrm{~cm}$. laterally, extended in the dorsal white matter of the left cerebrum from the anterior frontal region to the coronal level of the splenium of the corpus callosum. The external capsule and claustrum were destroyed but the basal ganglia and ependyma were intact. The walls of the cavity, after

TABLE II

GROUP II

\begin{tabular}{|c|c|c|c|c|c|}
\hline $\begin{array}{l}\text { Series } \\
\text { No. }\end{array}$ & Age & Sex & Side & Clinical Features & Necropsy Findings \\
\hline 11 & 12 & $\mathbf{F}$ & $\mathbf{L}$ & $\begin{array}{l}\text { Admitted unconscious. No history } \\
\text { available. Died in coma day after } \\
\text { admission }\end{array}$ & $\begin{array}{l}\text { Serpentine angioma of vein of corpus striatum, its tributaries, and lesser } \\
\text { vein of Galen. Haematoma in centrum semiovale. Ventricular } \\
\text { haemorrhage. Microscopy: arteriovenous hamartoma; mainly } \\
\text { venous (Fig. 12) }\end{array}$ \\
\hline 12 & 9 & $\mathbf{M}$ & $\mathbf{L}$ & $\begin{array}{l}\text { "Collapsed" and admitted uncon- } \\
\text { scious. Died in coma day of } \\
\text { admission }\end{array}$ & $\begin{array}{l}\text { Aneurysmal dilatation of vein of corpus striatum. Rupture. Haematoma } \\
\text { in centrum semiovale. Ventricular haemorrhage. No microscopic } \\
\text { preparations }\end{array}$ \\
\hline 13 & 11 & $\mathbf{M}$ & $\mathbf{L}$ & See case report & See case report \\
\hline 14 & 15 & $\mathbf{F}$ & $\mathbf{R}$ & $\begin{array}{l}\text { "Collapsed" and brought to hospital } \\
\text { unconscious. Died within an hour } \\
\text { of admission }\end{array}$ & $\begin{array}{l}\text { Arteriovenous hamartoma of lesser vein of Galen, its tributaries, and of } \\
\text { arteries supplying thalamus. Small haematoma in thalamus. Ventri- } \\
\text { cular haemorrhage. Diffuse subarachnoid haemorrhage (Figs. } 8 \text { and 9) }\end{array}$ \\
\hline
\end{tabular}




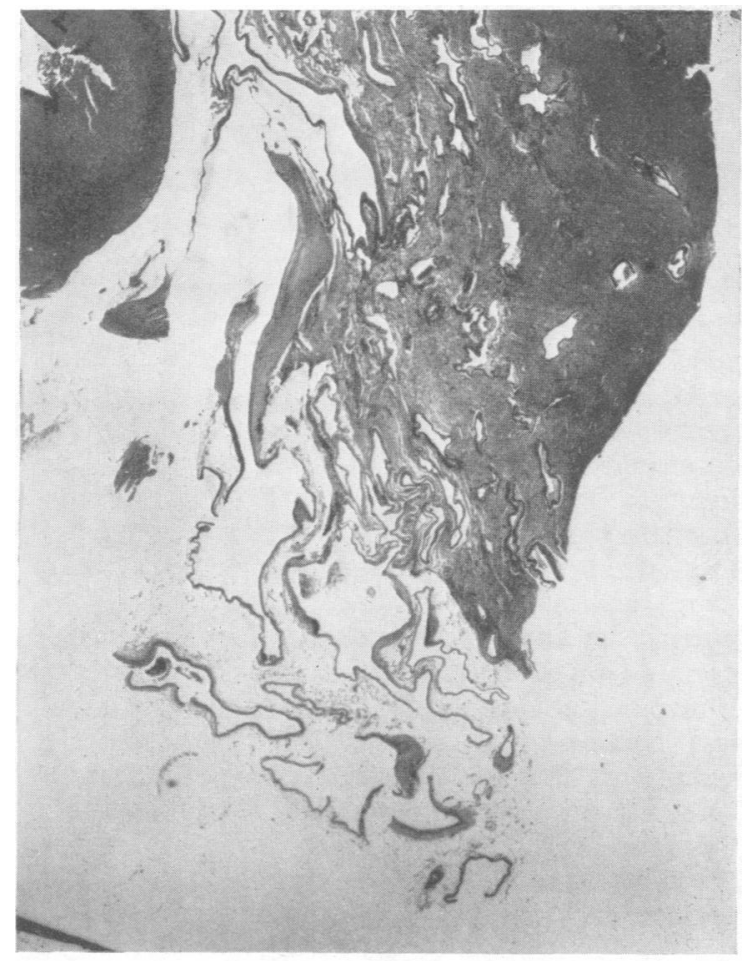

FIG. 8

evacuation of the clot and fixation of the brain, were greatly softened and stippled with haemorrhages. In the corona radiata forming the medial wall, and adjacent to the head of the caudate nucleus, the white matter appeared friable and contained a few enlarged blood vessels with thickened grey walls. This area measured about 0.7 by $0.5 \mathrm{~cm}$. Apparently draining from this focus was an enlarged $(0 \cdot 2 \mathrm{~cm}$. diameter) but thin-walled vein which traversed the posterior part of the head of the caudate nucleus, beneath the ependyma, to unite with the choroid plexus close to the foramen of Monro.

Microscopic Examination.-As shown in Fig. 10, the area identified in the medial wall of the haemorrhage contains grossly abnormal vessels. Stains for elastic demonstrate the presence of arteries as well as veins, though the latter are more conspicuous in respect of enlargement and number. There can be no doubt that this malformation was responsible for the haemorrhage in view of its intimate relationship to the latter.

Fig. 8.-Case 14. Area of pulvinar occupied by grossly malformed vessels. Phosphotungstic-acid haematoxylin. $\times 9$.

Fig. 9.-Case 14. Adjacent to Fig. 8, to show both arterial and venous elements in malformation. Verhoeff's elastic and van Gieson. $\times 17$.

Fig. 10.-Case 13. Area containing malformed vessels in medial wall of haematoma. Masson's trichrome. $\times 6$.

FIG. 10
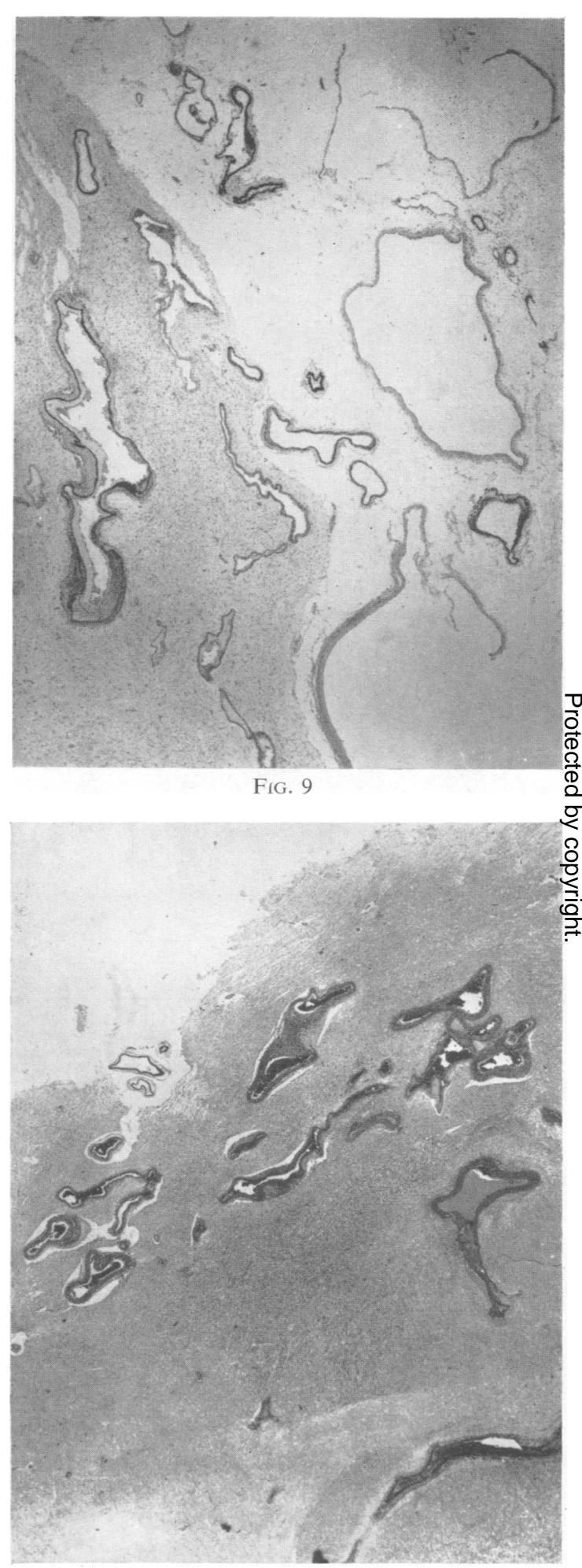


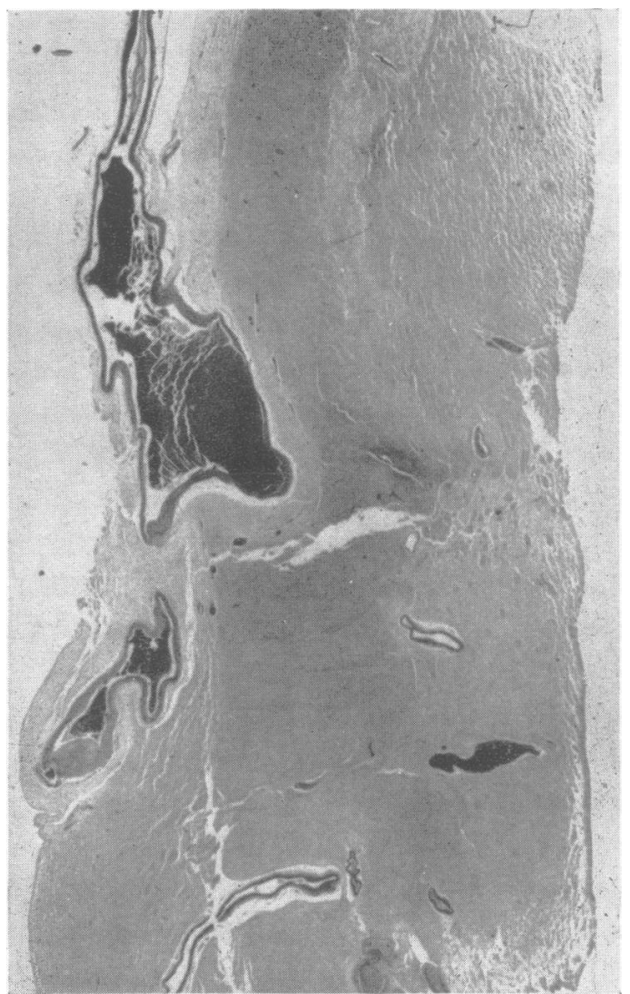

Fig. 11.-Case 11. Dilated malformed vein of corpus striatum. Verhoeff's elastic. $\times 5$ approx.

\section{GROUP IUI}

There are six cases in this cerebellar group; three proved rapidly fatal, while the other three were relieved by operative treatment (Table III).

\section{Clinical Summary}

The three fatal cases cannot be distinguished clinically from the similarly catastrophic examples in the preceding groups. The remaining three presented features (as exemplified by Case 20) which strongly suggested a rapidly growing cerebellar tumour. They each had a history of several weeks of increasing intracranial pressure, and developed well marked signs of cerebellar dysfunction. Indeed, the disclosure of an intracerebellar haematoma at operation in Case 19 was considered to be due to a capillary haemangioblastoma, and a search was made for a mural nodule ; a suspected portion of the wall removed for microscopic examination revealed merely organizing blood clot. It was not until 15 months later, when re-exploration was necessary on account of the recurrence of symptoms, that the area containing the vascular hamartoma in the white matter of the lower vermis was found and removed. As in Group I, therefore, the distinction between the type of lesion under present consideration and a true neoplasm may only be made on occasion by operative measures.

\section{Pathology}

Although the cerebellum appears less frequently as the site of gross spontaneous haemorrhage in the vascular anomalies under discussion, it is not? हु

TABLE III

GROUP III

\begin{tabular}{|c|c|c|c|c|c|}
\hline $\begin{array}{l}\text { Series } \\
\text { No. }\end{array}$ & Age & Sex & Clinical Features & $\begin{array}{l}\text { Site of } \\
\text { Lesion }\end{array}$ & Pathological Findings \\
\hline 15 & 17 & $\mathbf{M}$ & $\begin{array}{l}\text { Collapsed in street. Had a fit. Brought to } \\
\text { hospital. Died on admission }\end{array}$ & $\begin{array}{l}\text { Right cerebellar } \\
\text { lobe }\end{array}$ & $\begin{array}{l}\text { Venous hamartoma. Rupture. Meningeal haemor- } \\
\text { rhage. Microscopy: venous hamartoma } \\
\text { occupying white matter }\end{array}$ \\
\hline 16 & 7 & $\mathbf{M}$ & Brought to hospital dead. No history available & $\begin{array}{l}\text { Superior medul- } \\
\text { lary velum }\end{array}$ & $\begin{array}{l}\text { Venous hamartoma. Haemorrhage in fourth } \\
\text { ventricle and meninges. Microscopy : mainly } \\
\text { venous, also arterial hamartoma }\end{array}$ \\
\hline 17 & 11 & $\mathbf{M}$ & $\begin{array}{l}\text { Sudden onset severe headache and vomiting } \\
\text { followed by a fit. Lost consciousness, and } \\
\text { died in coma day of admission }\end{array}$ & Superior vermis & $\begin{array}{l}\text { Haematoma in superior vermis and both lateral } \\
\text { lobes. No vascular abnormality noted. Sub- } \\
\text { arachnoid and subdural haemorrhage. Micro- } \\
\text { scopy : arteriovenous hamartoma in deep } \\
\text { sulcus and white matter of superior vermis }\end{array}$ \\
\hline 18 & 22 & $\mathbf{F}$ & $\begin{array}{l}\text { Four months of increasing headache. Papill- } \\
\text { oedema and nystagmus. Recorded symp- } \\
\text { tom free } 15 \text { months after operation }\end{array}$ & $\begin{array}{l}\text { Left cerebellar } \\
\text { lobe }\end{array}$ & $\begin{array}{l}\text { Operation-haematoma in left lobe evacuated. } \\
\text { Large vessels in wall coagulated with diathermy. } \\
\text { Biopsy from wall: granulation tissue and } \\
\text { gliosis only }\end{array}$ \\
\hline 19 & 16 & $\mathbf{M}$ & $\begin{array}{l}\text { Two weeks increasing headache and drowsi- } \\
\text { ness. Papilloedema and nystagmus. Left } \\
\text { cerebellar haematoma evacuated. Fifteen } \\
\text { months later recurrence and solid nodule } \\
\text { removed at operation }\end{array}$ & $\begin{array}{l}\text { Posterior vermis } \\
\text { and left lobe }\end{array}$ & $\begin{array}{l}\text { Second operation-tumour-like mass }(3 \mathrm{~cm} \text {. } \\
\text { diameter) removed from posterior vermis. } \\
\text { Microscopy : arteriovenous hamartoma }\end{array}$ \\
\hline 20 & 33 & $\mathbf{M}$ & See case report & $\begin{array}{l}\text { Left cerebellar } \\
\text { lobe }\end{array}$ & See case report \\
\hline
\end{tabular}




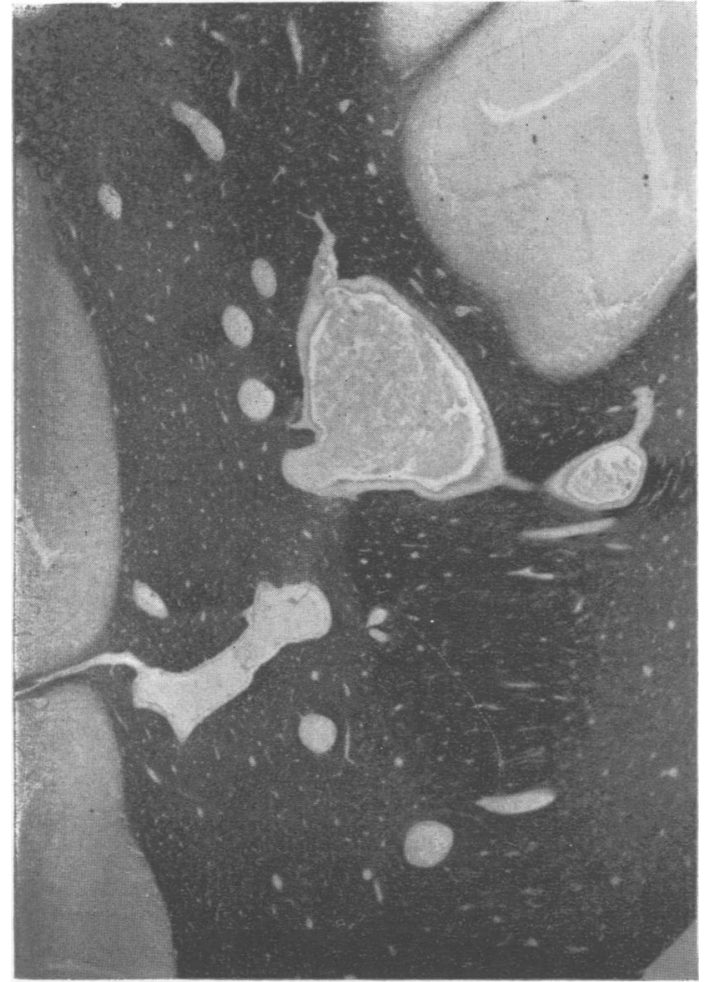

Fig. 12.-Case 13. Small unruptured venous hamartoma in white matter of lateral lobe of cerebellum. Loyez' haematoxylin. $\times 12$.

uncommon, in the routine macroscopic examination of sections of fixed specimens, to encounter small and clinically silent lesions of this kind without any alteration of the vessels in the adjacent leptomeninges. Such an example is illustrated in Fig. 12 ; it was identified as a minute pinkish-red area in the central white matter of a lateral lobe during scrutiny of the fixed brain for an unrelated neurological condition. Histologically it appears to be entirely venous. It is therefore possible that vascular hamartomas of the cerebellum are less apt to rupture than the cerebral examples. But it will be appreciated also that lesions of the dimensions illustrated may easily be so destroyed in the event of a massive haemorrhage that their subsequent identification by the pathologist is impossible. In the three fatal cases necropsy revealed considerable haemorrhage in the basal cisterns and regional leptomeninges; in one (Case 17) there was also basal subdural haemorrhage. The site of the intracerebellar haemorrhage varied : analysing all six cases a lateral lobe was alone involved in three ; the vermis, with spread into one or both lateral lobes, in two; in the sixth, the haemorrhage arose from vessels in the superior medullary velum and caused extensive intraventricular haemorrhage.

Microscopically the lesion was composed of both abnormal arteries and veins in three examples (Cases 16, 17, and 19) and of veins alone in one (Case 15). In the remaining two cases the composition remains uncertain since no histological verification was obtained in one, and in the other (Case 20) the histological report (from another laboratory) neglects this point and the material is no longer available for re-examination.

\section{Illustrative Case}

Case 20 (Neurosurg. No. 910/41). -A man, aged 33, was admitted to Chase Farm Hospital on May 28, 1941.

Clinical History.-For one month he had had occipital headache and giddiness in which he " felt he was spinning to the right ". He also complained of diplopia on looking to the left. Examination showed bilateral papilloedema, and sluggish pupils with coarse nystagmus on deviation to the right. There was weakness, hypotonia and ataxia of the left arm and leg. On May 30, a suboccipital craniotomy revealed broadening and flattening of the folia of the left cerebellar lobe; incision disclosed a haematoma, $3 \mathrm{~cm}$. diameter, surrounded by ragged brownish membrane. There was nothing suggesting a mural nodule, but crossing the depth of the cavity was a prominent vcssel resembling an artery, and there were a number of vessels in the wall of the cavity which bled very freely. Tissue from the wall of the cavity was taken for histological examination. The patient made a satisfactory recovery following this operation. At the time of his discharge (June 22) he was symptom free and nystagmus was the only residual sign. When last seen (March 27, 1942) he was free of symptoms and working steadily.

Ill-sustained nystagmus to the right was the only abnormal finding.

Biopsy.-The specimen was reported from Chase Farm Hospital as "semi-necrotic tissue containing numerous thin-walled dilated vessels, and thicker strands of collagen probably derived from larger vessels". The material is no longer available for reexamination.

\section{DISCUSSION}

Although 12 of the 20 cases in this series proved rapidly fatal, certain others (in Groups I and III) were relieved by operation. In retrospect, the lesions in Cases 5 and 6 also might have been satisfactorily removed had their true nature been appreciated at the time. But the clinical diagnosis may prove extremely difficult.

Case 8 exhibited typical features, and no diagnostic problem. She was a young person with a sudden onset of hemiplegia, but only partial impairment of consciousness, and with no previous hint of any cerebral lesion. Angiography revealed 
the vascular hamartoma and intracerebral haematoma, which were then removed. The slower tempo of the neurological disturbance exemplified by Cases 4 and 10 was less typical. The history in these was thought to indicate a malignant glioma, and the true nature of the lesion was revealed when, in each, an intracerebral haematoma was tapped during ventriculography. Such occurrences emphasize the importance of attempting to establish an exact diagnosis in all such cases, even though the clinical picture may strongly suggest an inoperable lesion. For this purpose, electroencephalography, angiography, and ventriculography may all be required. Sometimes craniotomy, with a biopsy if possible, may be the only means of establishing the correct diagnosis. Moreover, the risks entailed by delay in such cases are obvious ; not only may a further and fatal haemorrhage occur, as in Case 6, but a persistent serious disability may result, as in Case 8, where the transfer of the patient from another hospital was too long delayed.

Angiography showed a vascular lesion in two cases (6 and 8$)$ of this series. In Case 6 the significance of the abnormal focus of blood vessels was controversial and no surgical intervention was undertaken. In two other cases (7 and 10) angiography was performed but no abnormal vascular filling was seen. It must be accepted that some of these cryptic vascular hamartomas are so small that they may pass undetected or even fail to fill in the angiogram. It is likely that a higher proportion will be detected by serial angiography. In the two cases in which no abnormal vessels were seen, the vascular displacement of a space-occupying lesion, i.e., a haematoma, was seen, so that the angiograms were of value. However, in Case 6 , referred to above, there was no vascular displacement, and this added to the difficulty in diagnosis. We may thus regard angiography as a highly important investigation, but it is by no means conclusive in every case. Ventriculography may furnish supplementary information.

In Cases 7 and 9 there was a history of mild antecedent trauma to the head, and the diagnosis of subdural haematoma was considered. Our clinical histories do not fully establish how frequently trauma precedes cerebral haemorrhage in these cases, but it was also noted in two of four examples of vascular hamartoma reported by Margolis, Odom, Woodhall, and Bloor (1951). This factor may be relevant to the problem of Spätapoplexie, postulated by Bollinger in 1891. It is also of medicolegal importance, for the coroner's pathologist may misinterpret his observations in dealing with these cryptic hamartomas unless a careful scrutiny of the brain is made. In Case 5 pregnancy was probabl the inciting cause of the rupture; the patient blood pressure was normal at the time.

In Group II our data suggest that both the situation of the vascular lesion and the distribution of the haemorrhage render it improbable that an effective treatment is possible. These cases were a\& rapidly fatal. Sterzing (1908) recorded an examp of this group, however, in a man aged 32 who survived a right hemiplegia, with speech defect from the age of 10 , and finally died from a further haemorrhage. At necropsy a collection of abnorma vessels was disclosed in the corpus striatum, ex tending towards the ventricle at the caudate nucleus and uniting with the vessels of the choroid plexus As far as we are aware this is the only instance ơ survival from haemorrhage when the vascula $\vec{\oplus}$ anomaly has been of the Group II type.

The recognition of small venous and arterios venous hamartomas in the cerebellum is of particulat importance, first because this part of the brain regarded as relatively immune, and secondly because their clinical recognition may lead to lifesaving treatment (Cases 18 to 20). As we havie already indicated the clinical distinction betwege these and rapidly growing cerebellar tumoots, especially cystic varieties, and also abscesses difficult and, at operation, the finding of a haema? toma may provoke the diagnosis of capillâro haemangioblastoma unless the abnormal vessels are identified.

We have thought this series of cases worthy record because the cryptic hamartomas have received little attention in the literature. Norais (1945), in a general review of the intracraniap vascular tumours and malformations, recognizeo that these lesions may be clinically silent an revealed only at necropsy. In illustration he quotes. two cases in which the vascular anomaly (apparentlos venous) was discovered only on microscopy ; onê lay in the subcortical cerebral white matter, the other was in the cerebellum and pineal region. The most important contribution to the subject fron this angle is that of Margolis and others (1951) From the post-mortem study of six cases, in fou of which fatal haemorrhage was attributable to. small vascular malformations, they identified three in which an arteriovenous (Case 1) or venous (Cases 3 and 4) lesion was responsible; in the first the depths of a left parietal sulcus and the adjacent brain were involved, in Case 3 it las. anterior to the right caudate nucleus, and in Case a tributary of the left lesser vein of Galen was responsible. In their Case 2 the lesion was pontine and, from the description, was perhaps a cavernous 
hamartoma. These authors specially mention the liability of young subjects to be affected by spontaneous haemorrhage, the sudden onset of symptoms with delayed loss of consciousness, and the occasional history of slight trauma. Approaching the problem of subcortical haematomas in nonhypertensive subjects from the surgical angle, Werner (1954) has found the pathogenesis obscure in his series of eight treated cases. Since these were all in young and middle-aged adults it is probable that some at least were of the kind we have described in Group I.

We conclude by quoting Dandy (1928) who states that it is

" a fairly safe, but not absolute, rule that when a cerebral hemorrhage occurs during youth or middle age, i.e., before the time when vascular accidents are to be expected, there must be an underlying tumor or aneurysm, either of which will contribute defective vessels".

"Aneurysm" here implies an arteriovenous malformation.

\section{SUMMARY}

Twenty cases of spontaneous cerebral and cerebellar haemorrhage in young subjects, due to small arteriovenous or venous hamartomas of the brain, are reported.

The term "cryptic" is proposed for such hamartomas on account of their latent character clinically and the pathological features.

The cases are divided into three groups on an anatomical basis: (I) related to the cerebral convexities ; (II) central cerebral ; (III) cerebellar.

Seven of the cases survived operation; the remaining 13 were demonstrated at necropsy.

Clinically the cases presented either as catastrophic apoplexies or, less acutely, simulating rapidly growing neoplasms.

Figs. 3 and 10 reproduced by courtesy of the Editor of Proceedings of the Royal Society of Medicine.

\section{REFERENCES}

Dandy, W. E. (1928). Arch. Surg., Chicago, 17, 715.

Margolis, G., Odom, G. L., Woodhall, B., and Bloor, B. M. (1951). J. Neurosurg., 8, 564

Noran, H. H. (1945). Arch. Path. (Chicago), 39, 393.

Russeli, D. S. (1954). Proc. roy. Soc. Med, 47, 689.

Sterzing, P. (1908). Zbl. allg. Path. path. Anat., 19, 278.

Werner, A. (1954). Journal of Neurology, Neurosurgery and Psychiatry, 17, 57. 